\title{
Comparison of the mechanical properties and microstructural evolution in the HAZ of HSLA DOMEX 700MC welded by gas metal arc welding and electron beam welding
}

\author{
Peter Kopas ${ }^{1, *}$, Milan Sága ${ }^{1}$, Michal Jambor ${ }^{2}$, František Nový $^{2}$, Libor Trško $^{3}$, Lenka \\ Jakubovičová ${ }^{1}$ \\ ${ }^{1}$ University of Zilina, Faculty of Mechanical Engineering, Department of Applied Mechanics, \\ Univerzitná 1, 010 26, Zilina, Slovak Republic \\ ${ }^{2}$ University of Zilina, Faculty of Mechanical Engineering, Department of Materials Engineering, \\ Univerzitná 1, 010 26, Zilina, Slovak Republic \\ ${ }^{3}$ Research Centre of the University of Žilina, Univerzitná 1, 010 26, Zilina, Slovak Republic
}

\begin{abstract}
High strength low alloyed steels are nowadays an important group of engineering materials, with numerous industrial applications. Properly chosen chemical composition together with the thermomechanical processing allow to reach high mechanical properties, while the carbon content is maintained low. Resulting microstructure is therefore sensitive to the amount of the heat introduced to the metal during welding. During welding procedure, softening phenomenon can occur in the heat affected zones and it could lead to the degradation of the mechanical properties of the final joint. Nowadays, welding technologies based on the high energy electron beam are able to produce weld joints with very narrow heat affected zone. In this study, authors compare mechanical properties and the microstructural evolution in the heat affected zone of the GMAW and EB welded joint of the DOMEX 700MC HSLA steel. The carried out experiments showed that both evaluated technologies are able to produce joints with appropriate mechanical properties. Welded joints made by the EBW technique showed slightly better mechanical properties of the whole joint, as a result of the narrower HAZ.
\end{abstract}

Keywords: HSLA, DOMEX 700MC, gas metal arc welding (GMAW), electron beam welding (EBW)

\section{Introduction}

In the last decade, the high strength low alloyed (HSLA) steels became the standard material used in the engineering constructions. This category of materials offers the higher mechanical properties than standard grades of weldable structural steels, what allow to reach significant reductions of the total component's mass, as the cross-section of components can be reduced. Improved mechanical properties of the high strength low alloyed steels thanks to the carefully

\footnotetext{
*Corresponding author: peter.kopas@fstroj.uniza.sk

Reviewers: Wieslawa Piekarska, Milan Nad'
} 
designed chemical composition together with the thermomechanical processing, resulting in the fine-grained microstructure of the final products [1-5].

It the numerous engineering applications, the welding is the most widespread joining technology. The high strength low alloyed steels owe for their properties fine-grained microstructure, and the heat introduced to the material during welding procedure can significantly affect microstructure in the heat affected zone a degrade resulting mechanical properties of the weld joint [6-9]. To obtain appropriate mechanical properties of the weld joint of the high strength low alloyed steels welding process has to be carefully designed, to reduce the amount of the heat introduced to the materials and prevents to the softening in the heat affected zone [10]. Modern welding techniques, which use high energy beams, allows to minimize the amount of heat introduced to the joint and obtaining very narrow heat affected zone. On this bases, electron beam and laser beam welding techniques are very interesting options for the welding of high strength low alloyed steels [11-13].

This study compares mechanical properties and the microstructural evolution in the heat affected zone of weld joint of high strength low alloyed steel DOMEX 700MC, obtained by the gas metal arc welding (GMAW) and electron beam welding techniques (EBW).

\section{Materials and methods}

In the presented study, high strength low alloyed DOMEX 700MC steel of $10 \mathrm{~mm}$ thickness was used as an experimental material. The DOMEX 700MC steel belongs to the group of HSLA steels with ferritic structure. The chemical composition and the mechanical properties of experimental material are shown in Tables 1 and Table 2. High values of ultimate tensile strength and yield strength of DOMEX 700MC steel are achieved by the combination of properly chosen chemical composition and thermomechanical processing, what results in very fine ferritic microstructure with uniformly dispersed fine cementite particles (Fig.1).

Table 1. Basic mechanical properties guaranteed by the supplier

\begin{tabular}{|c|c|c|c|}
\hline \multirow{2}{*}{ DOMEX 700MC } & $\begin{array}{c}\text { Ultimate tensile } \\
\text { strength [MPa] }\end{array}$ & $\begin{array}{c}0.2 \text { offset Yield } \\
\text { strength [MPa] }\end{array}$ & $\begin{array}{c}\text { Tensile elongation } \\
{[\%]}\end{array}$ \\
\cline { 2 - 4 } & $750-950$ & min. 700 & min. 12 \\
\hline
\end{tabular}

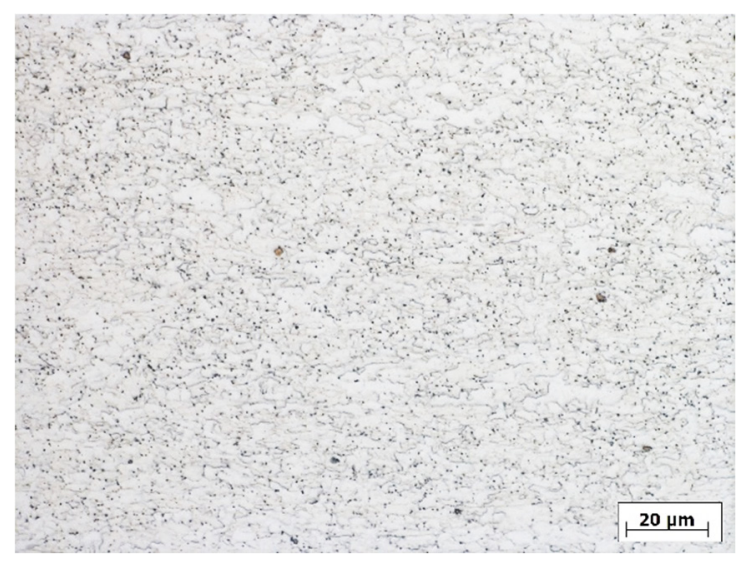

Fig. 1. Microstructure of the DOMEX 700MC HSLA steel 
Table 2. The chemical composition of the DOMEX 700MC guaranteed by the supplier

\begin{tabular}{|c|c|c|c|c|c|c|c|c|c|}
\hline \multirow{3}{*}{ DOMEX 700MC } & $\mathrm{C}$ & $\mathrm{Si}$ & $\mathrm{Mn}$ & $\mathrm{P}$ & $\mathrm{S}$ & $\mathrm{Al}$ & $\mathrm{Nb}$ & $\mathrm{V}$ & $\mathrm{Ti}$ \\
\cline { 2 - 10 } & $\max$. & $\max$. & $\max$. & $\max$. & $\max$. & $\min$. & $\max$. & $\max$. & $\max$. \\
& 0.12 & 0.10 & 2.10 & 0.025 & 0.01 & 0.015 & 0.09 & 0.2 & 0.15 \\
\hline
\end{tabular}

Two different welding methods were used for the welding of the HSLA DOMEX 700C steel. The GMAW and EB welding. As a preparation for the GMAW procedure, metal sheets were mechanically cleaned before welding and degreased by the acetone. The gap $2 \mathrm{~mm}$ was maintained between the sheets and their edges were cut at angle of $50^{\circ}$. The OK AristoRod 69 wire with diameter $1.2 \mathrm{~mm}$ was used as a filler metal. For the optimization of GMAW process, several welds were prepared with the welding parameters in the range: voltage $23-30 \mathrm{~V}$, current $145-300 \mathrm{~A}$ and the welding speed 3-8 mm/s. The welding parameters were chosen to obtain a stable welding process with the high quality of final welds, without any macroscopic geometrical and internal defects. As a result of the optimizing process, the following welding parameters were used for the preparation of the testing specimens. For root layer: voltage $23.3 \mathrm{~V}$, current $164 \mathrm{~A}$ and welding speed $4.8 \mathrm{~mm} / \mathrm{s}$ and for the top layer: voltage $28.2 \mathrm{~V}$, current $230 \mathrm{~A}$ and the welding speed $5 \mathrm{~mm} / \mathrm{s}$. Similarly, before the EB welding, sheets were again mechanically cleaned and degreased in acetone and after optimization of the welding process, the following parameters were chosen for the preparation of final welds: acceleration voltage $55 \mathrm{kV}$, current $115 \mathrm{~mA}$ and the welding speed $11 \mathrm{~mm} / \mathrm{s}$.

Mechanical properties of the weld joints were obtained by the standard tensile tests. Tree specimens of each type of weld were used, and the average values were calculated. For the evaluation of the properties in the individual areas of weld joint (weld metal - WM and heat affected zone - HAZ), microhardness measurements were performed. Evolution of the microstructure, mainly in the HAZ was examined by optical microscopy.

\section{Results and discussion}

Macro and microscopic observations of the welds revealed significant differences. The width of the HAZ and the weld metal zone (WM) were significantly larger for the GMAW process (Fig.2). In both welds, two different regions in HAZ were identified. The evolution of the microstructure in the HAZ depends on the thermal cycle to which was exposed during the welding process. Closer to the weld metal (WM), coarse-grain HAZ was observed (CGHAZ). These areas are during the welding completely transformed to the austenite, then coarse and during subsequent cooling transform back to the ferrite. The thickness of this zone was considerably larger for the GMAW as a result of the larger heat input during GMAW process, which result in the longer exposures of that zone in the austenite region. CGHAZ in the EB welds was significantly narrower, but the grain size in that area was larger (Fig. 3a, b) than in the GMAW welds. This phenomenon can be explained that during the EB welding process, the high energy beam input a large amount of heat energy in a very short time, thus the heat has no sufficient time to dissipate in the metal and the maximum reached temperature in the CGHAZ is higher than for the conventional GMAW process. With increased distance from the weld metal, the microstructure changed and the fine-grained HAZ (FGHAZ) was observed in both welds (Fig. 3c, d). During the thermal cycle, these zones were heated to the austenitic area for a very short period of time, thus no coarsening could occur. The thickness of this zone was larger for the GMAW weld, especially in the root area. Between the FGHAZ and base metal, the transition area was observed. The temperature reached in this area during the welding procedure was very close to the $\mathrm{AC}_{1}$ temperature, thus the resulting microstructure is only partially recrystallized and the phenomenon as a polygonization and recovery took place in this area (Fig. 3e, f). 

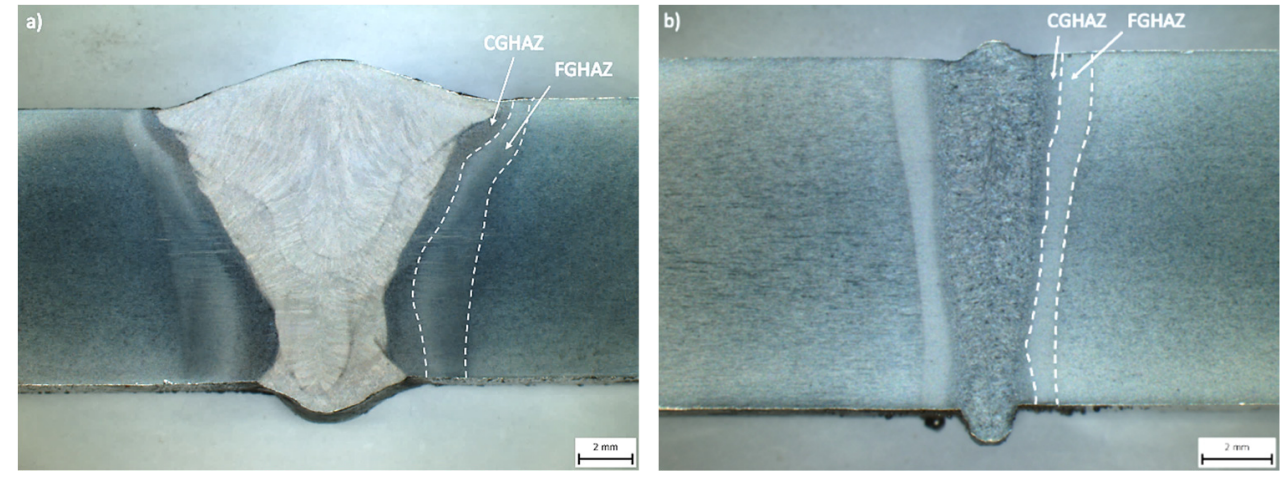

Fig. 2. Macroscopic view of the examined weld joints, a) GMAW, b) EBW
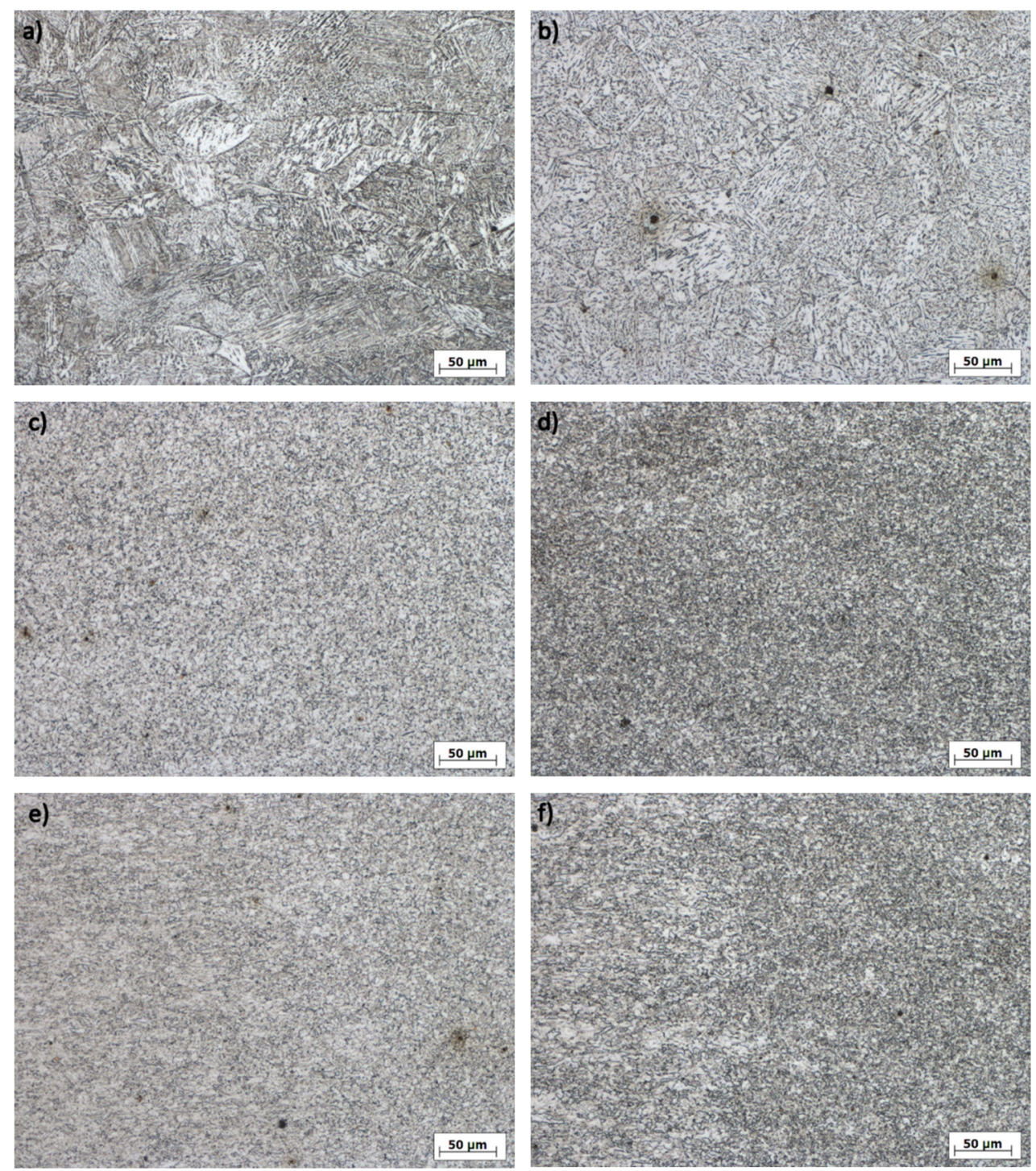

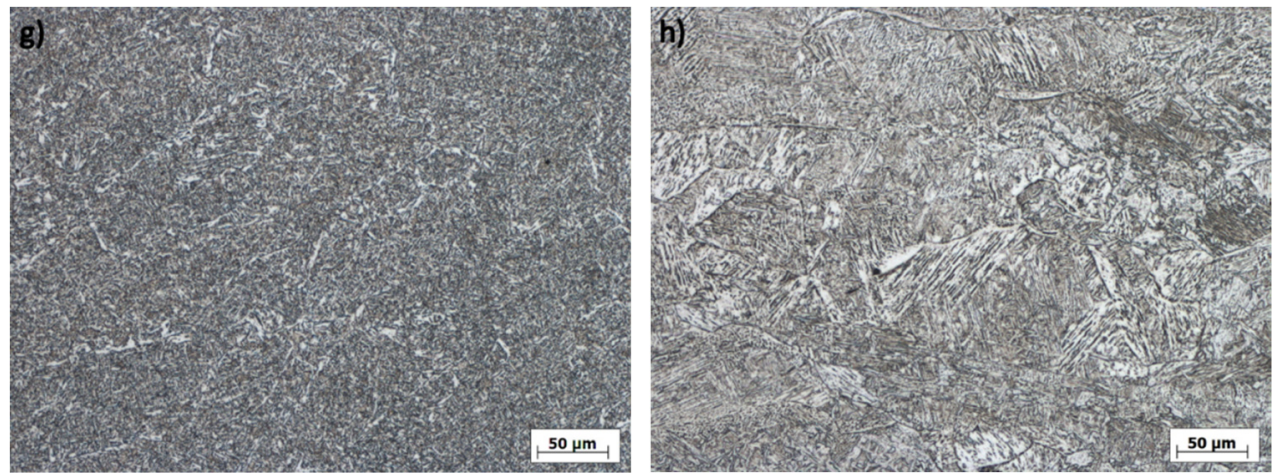

Fig. 3. Microstructures of the HAZ

Figures a, $\mathrm{c}$ and e represents CGHAZ, FGHAZ, resp. transition zone of GMAW joint.

Figures $\mathrm{b}, \mathrm{d}$ and $\mathrm{f}$ represent CGHAZ, FGHAZ and transition zone of EBW joint.

Microhardness measurement examined mechanical properties of all areas of the weld joints. The results of the microhardness measurements are shown in the Fig.4. Based on the results, in the GMAW weld, the most critical part is the HAZ, especially transition region between the FGHAZ and the base metal (BM). Average values of microhardness in the BM was 276 HV1 and for the WM values $261 \mathrm{HV} 1$ were recorded. In the HAZ, the highest average values were recorded in the CGHAZ (252 HV1), then in the FGHAZ (235 HV1) and the lowest values were recorded in the transition region between the FGHAZ and the BM (210 HV1).

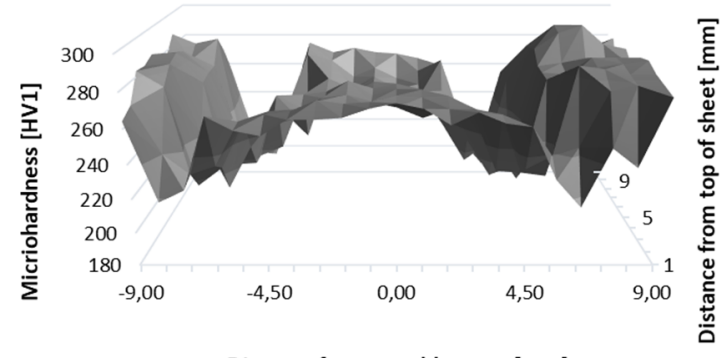

Distance from a weld center [mm]

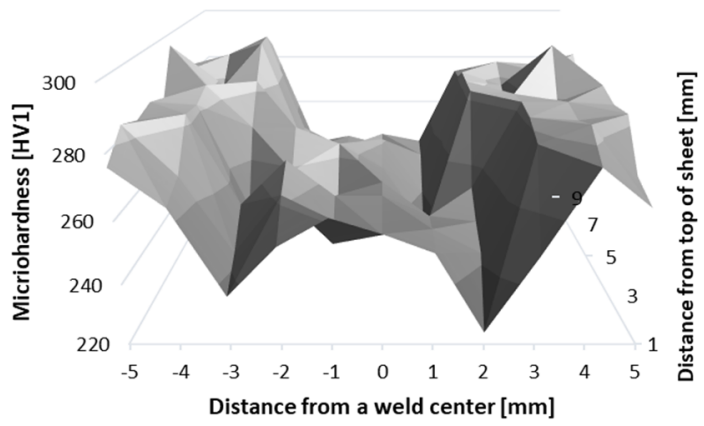

Fig. 4. The results of the microhardness measurements, top - GMAW, the bottom - EBW

The electron beam weld microhardness measurements had slightly different results. The mainly, in the EBW process, there was not used any filler metal, thus the WM zone is a 
remelted parent material, and this corresponds with the measured values of microhardness (256 HV1). Microhardness values in the HAZ vary for different subzones, but the differences were significantly smaller than in the HAZ of GMAW weld. The average value in CGHAZ was $252 \mathrm{HV}$, in the FGHAZ 243 and finally, in the transition region, the average value 236 HV1 was recorded. These observations are in consistency with other authors [14].

Results of the tensile tests are shown in Table 3. Specimens welded by the GMAW were broken in the HAZ, what suggests that the softening in the heat affected zone recorded by the microhardness measurements has a significant effect on the resulting properties of the weld joint. Even that the specimens were broken in the softened regions of HAZ, the measured values of yield strength and ultimate tensile strength still fulfil the requirements for the mechanical properties of the DOMEX 700MC. For the specimen welded by the electron beam, the different behaviour was observed. However, the softening in the HAZ was observed also in the EB weld, this was not so significant and the specimens were broken in the weld metal zone. This suggests that use of EB welding results in the production of very narrow HAZ, in which the level of softening is lower than in the weld made by conventional GMAW. Results of the tensile test showed higher values of ultimate tensile strength, yield strength and tensile elongation for the weld made by electron beam welding compared with the GMAW. The most significant difference is in the values of YS, which were about 57 MPa higher for the EB weld.

Table 3. Results of the tensile tests

\begin{tabular}{|c|c|c|c|}
\hline & UTS [MPa] & 0.2 offset YS [MPa] & Tensile elongation [\%] \\
\hline DOMEX 700MC GMAW & 783.5 & 691.4 & 9.1 \\
\hline DOMEX 700MC EBW & 793.3 & 748.8 & 12.2 \\
\hline
\end{tabular}

Both examined welding technologies were able to produce joints with sufficient mechanical properties. The phenomenon of softening in the HAZ was recorded in both, GMAW and EBW welds, but was more significant in the weld joint made by conventional GMAW. The EBW produces markedly narrower HAZ, and the resulting properties of the joints made by EBW were higher. It is however questionable if the very high operating cost of the using EBW procedures are worth of the small advantages in the slightly higher YS introduced by the EBW process.

\section{Conclusions}

Based on the carried out tests and analysis, the following can be concluded:

- Both used method, GMAW and EBW are able to produce high-quality weld joint, with appropriate mechanical properties.

- In the HAZ, several subzones (CGHAZ, FGHAZ and transition region) were identified in both examined welds. In the EBW joint, the narrower HAZ was recorded, same as the thickness of individual subzones was lower.

- The softening of HAZ was observed in both tested joints, but it should be pointed out that the level of softening was significantly lower in EBW joint.

- Based on the result of the tensile test, in the GMAW joint, the most critical zone is the transition zone between the FGHAZ and BM, as the all tensile specimens were broken in that area. This is with consistency of the microhardness measurements, where the lowest values of microhardness were recorded in the transition area.

- Even in the EBW joint, softening of HAZ was recorded, this was not so significant. Tensile test specimens were broken in the WM area.

- Tensile tests showed that the weld joints made by EBW exhibits about $57 \mathrm{MPa}$ higher yield strength and about 3\% higher tensile elongation. 
This work was supported by the Slovak Research and Development Agency under the contract No. APVV-14-0096 and No. APVV-16-0276. Also this research was supported by Scientific Grant Agency of the Ministry of Education, Science, Research and Sport of the Slovak Republic under the contract VEGA No. 1/0951/17.

\section{References}

1. V. Sharma, A. S. Shahi, Quenched and tempered steels welded with micro-alloyed based ferritic fillers. Journal of Materials Processing Technology, 253, 2-16 (2018)

2. S. Błacha, M. S. Węglowski, S. Dymek, M. Kopyściański, Microstructural and Mechanical Characterization of Electron Beam Welded Joints of High Strength S960QL and Weldox 1300 Steel Grades. Archives of Metallurgy and Materials, 62, Issue 2A, 627-634 (2017)

3. K. Borko, B. Hadzima, M. Neslušan-Jacková, Corrosion resistance of Domex 700 steel after combined surface treatment in chloride environment. Procedia Engineering, 192, 58-63 (2017)

4. D. Arsic, V. Lazic, R. Nikolic, S. Aleksandrovic, B. Hadzima, M. Djordjevic, Optimal welding technology of high strength steel S690QL. Materials Engineering, 22, 33-47 (2015)

5. R. Ulewicz, P. Szataniak, Fatigue cracks of Strenx steel. Materials Today: Proceedings, 3, No. 4, 1195-1198 (2016)

6. L. Jakubovičová, B. Ftorek, V. Baniari, A. Sapietová, T. Potoček, M. Vaško, Engineering Design of a test device. Procedia Engineering, 177, 520-525 (2017)

7. Handrik, M., Vaško, M., Design of a computational model for multi-body contact of deformable bodies in the flowing fluid. Matec Web of Conferences, 157 (2018)

8. X. Qiang, X. Jiang, F. S. Bijlaard, H. Kolstein, Mechanical properties and design recommendation of very high strength steel S960 in fire. Engineering Structures, 112, 60-70 (2016)

9. R. Oyyaravelu, P. Kuppan, N. Arivazhagan, Metallurgical and mechanical properties of laser welded high strength low alloy steel. Journal of Advanced Research, 7, 463-472 (2016)

10. M. Mazur, R. Ulewicz, F. Nový, P. Szataniak, The structure and mechanical properties of Domex 700 MC steel. Communications - Scientific Letters of the University of Zilina, 15, No. 4, 54-57 (2013)

11. R. Halama, A. Markopoilos, F. Fojtik, M. Fusek, Z. Poruba, J. Famfulík, Effect of stress amplitude on uniaxial ratcheting of aluminum alloy 2124-T851. Materialwissenschaft und Werkstofftechnik, 48 (8), 814-819 (2017)

12. M. Kubiak, T. Domanski, V. Dekýš, A. Sapietová, Measurement of strain during tension test of welded joint using multi-camera $3 D$ correlation system. Procedia Engineering, 177, 107-113 (2017)

13. P. Kováčiková, R. Bezdedová, J. Jr.Vavro, J. Vavro, Comparison of numerical analysis of stress-strain states of cast iron with vermicular graphite shape and globular graphite shape. Procedia Engineering, 136, 28-32 (2016)

14. A. Dzyubyk, V. Palash, I. Khomych, S. Hrynus, Optimization of welding modes for high strength low-alloy DOMEX 700 steel. Ukrainian Journal of Mechanical Engineering and Materials Science, 3, No. 2, 47-54 (2017) 